\title{
Client requirement representations and transformations in construction project design
}

Article

Accepted Version

Collinge, W. H. (2017) Client requirement representations and transformations in construction project design. Journal of Engineering, Design and Technology, 15 (2). pp. 222-241. ISSN 1726-0531 doi: https://doi.org/10.1108/JEDT-03-20160022 Available at https://centaur.reading.ac.uk/68351/

It is advisable to refer to the publisher's version if you intend to cite from the work. See Guidance on citing.

To link to this article DOI: http://dx.doi.org/10.1108/JEDT-03-2016-0022

Publisher: Emerald

All outputs in CentAUR are protected by Intellectual Property Rights law, including copyright law. Copyright and IPR is retained by the creators or other copyright holders. Terms and conditions for use of this material are defined in the End User Agreement.

$\underline{\text { www.reading.ac.uk/centaur }}$

\section{CentAUR}


Central Archive at the University of Reading

Reading's research outputs online 


\title{
Client requirement representations and transformations in construction project design
}

\begin{abstract}
Exploring how client requirements undergo representational and transformational shifts through the design process, a social semiotic framework is mobilized to examine a series of construction project representations of hospital department configurations in their context of use as meaning making resources. The analysis reveals how semiotic resource use is intrinsic to design work: the deployment and use of sign constructs influencing multiple processes including communications, relations between parties and stakeholder engagement. Supported by practitioner opinion, it is contended that construction project design work may be understood as social semiotic practice: both client parties and designers judiciously employing sign constructs to represent requirements in a process that can be politically sensitive, competitive and temporally constrained.
\end{abstract}

Keywords: hospitals; communications; social semiotics; requirements; briefing; design practices; visualization 


\section{Introduction}

Despite their centrality to the design process, the representational shifts that client requirements undergo in briefing work are seldom recognized or acknowledged by practitioners or commentators. This is in spite of briefing being recognised as a collaborative, social process (Barrett and Stanley, 1999) that demands effective communication between parties (Dainty et al., 2006; Emmitt \& Gorse, 2007). Although a wide variety of communications are used in design work (e.g. a written brief; rough sketches; formal drawings; computerized imagery; physical models), the role and significance of such resources to represent client requirements is deserving of further study. This paper re-focuses attention upon how the built environment needs of clients are expressed through their requirements: often initially detailed in a strategic brief, but then subsequently transformed by designers into drawings, images, models, etc. The paper will note how the representation of requirements through sign communications has multiple implications for the design process, including requirement interpretation, stakeholder engagement, intra-project relationships and project control.

The paper uses a series of requirement representations relating to hospital department configurations drawn from a hospital construction project and examines them with a social semiotic framework. It will be argued that although client requirements provide a tangible and ever-present link to client needs, the semiotic choice of representation and communication is motivated by human intention, and is intrinsic to the sharing of meanings. The paper builds upon the work of construction management academics who have identified meaning as pre-eminently important (e.g. Dainty et al. 2006), who have described briefing as a social process (e.g. Fernie et al. 2003; Fleming, 1996) and those who identify construction communication as a semiotic process (Gluch and Raisanen, 2009). The analysis clarifies how 
and why sign constructs are employed in design work for the making of meaning. Three broad contentions are made:

- Meanings are delivered through representations

- New meanings can be made through representations

- Project relationships are affected through such representations

The paper begins by reviewing the literature of design work practice, leading to a discussion of communication and the importance of shared understandings in briefing work. Social semiotic concepts are then presented together with a framework of analysis to be mobilized. A research methods section details how project material was sourced and how interviewees were identified. A series of project resources representing hospital departmental requirements are then examined in their context of use: a clinical adjacency matrix; Perspex blocks; a power point slide and a schematic drawing. The focused analysis of each resource as meaning making resource is supplemented by practitioner opinion and thought. A following discussion reflects upon the findings, highlighting how a social semiotic analysis supplements understandings of briefing communications: human motivation driving forward requirement representation via sign deployment between client and designers. A final conclusion draws the paper to a close.

\section{Design Work Practice}

A social perspective of design work can be traced back to Goodacre et al. (1982) who suggested that designers and client should work together in collaboration over time to enhance mutual knowledge. That briefing is a social process, rooted in the processes and interactions of design practice, has been recognized by subsequent commentators (e.g. Green, 1996; Barrett and Stanley, 1999), several of whom also challenged structured and reductionist takes of briefing work. For example, Kao and Green (2002) argued against a positivist view 
of briefing that has characterized some of the literature since the Latham Constructing the Team (1994) and Egan Rethinking Construction (1998) reports, stating,

"The information processing model of briefing, which takes it for granted that client requirements can be fully codified is questionable from a perspective of organisation knowledge transfer.” (p. 84-87)

Both Emmitt and Gorse (2007) and Fernie et al. (2003) also noted that briefing is a complex, social process that is iterative in nature. Blyth and Worthington (2001) commented that briefing and design are inextricably linked, both being reflective and interactive processes that should engage multiple stakeholder interests. Other work in the field recognizes the importance of user engagement in the briefing process (Barrett and Stanley, 1999) and differences between "traditional" and "more inclusive" briefing methodologies (Jensen and Pedersen, 2009).

Although such critiques point towards a social explanation and understanding of design work practice, scholars have generally stopped short of examining client requirements and how they are represented and understood through the briefing process. Indeed, if shared understandings are as important as scholars suggest (e.g. Green, 1996), then focusing upon how shared meanings and understandings are established and the role of client requirements in that process is important. Fleming (1996) identifies the significance of client and designer communicative events, when stating,

“The social and political relationship between designer and client was constructed within the project itself...In sum, social roles in design are best seen as constructed by interested participants in local rhetorical events." (p. 140-142)

The identification of "local rhetorical events" by Fleming points towards a focused analysis of particular communicative interchanges between client and designers. It follows that as 
briefing is primarily concerned with client requirements (i.e. understanding them; discussing them; visualizing them) and developing solutions to address them, then a focused analysis of client requirements through the design process is also worthy of study. Briefing and design communication is now considered in more detail.

\section{Design Communications}

Whilst different communicative methodologies are used in briefing work, such as discussions, meetings and run-throughs (Ryd, 2004), the design process is also characterized by the use of texts, drawings and visualizations, with an increasing use of Building Information Modelling (BIM) (Eastman et al., 2008), as project actors discuss and collaborate. Such resources are important for the making of meanings and shared understandings.

Lloyd and Busby (2001) highlighted the importance of language and word exchange in social interactions that mediate the problem solving process: designers using particular words to articulate their thoughts as opposed to architects, who prefer to use drawings and sketches. Bogers et al. (2008) reflected how designers often use images to clarify concepts for the client whilst Blyth and Worthington (2001) note the discrepancies in the choice of communication method, commenting:

"At an operational level design teams will be in the habit of communicating with visual aids, drawings and photographs, whereas the user may be more used to written reports and not familiar with the idiosyncrasies of a designer`s drawing." (p.9)

Many academics have observed that briefing involves the use of different semiotic resources, noting that requirements are "translated" from one communicative form (i.e. words) to another (i.e. drawing), including Markus and Cameron (2002), Kamara et al. (2000) and Blyth and Worthington (2001), who state, 
"Design and briefing are integral parts of the same process with much of briefing carried through the process of design. During this process the language used by the organization is converted into the language of building. The strategic brief is articulated through words and diagrams, while the project brief is articulated through conceptual drawings and workflow diagrams.” (p.21)

Client requirements, usually presented to designers in the form of a brief, provide an initial focus for interactions between client and designers. As design work commences, conceptual solutions are produced and communicated to the client (via drawings, images, etc.). In briefing work, communication occurs not just from person-to-person, but also from project resource to person: interactions between humans, drawings and images also being legitimate instances of communication. Official codes of practice for construction project management (e.g. Chartered Institute of Building, 2010) highlight effective communication as important whilst often underplaying the significance of interpretative processes in acts of communication. Whereas "meaning" and "understanding" may be mentioned in such texts, they are critically important for any communicative act to be effective, and these concepts are dependent upon shared signs. As Dainty et al. (2006) acknowledge,

"Although (schematic models) are useful for conceptualizing communication as a process, this masks the complex interplay of signs, meanings and symbols (semiotics) which are often more important than the explicit communication itself" (p.59)

Indeed, communication may be effective but unsuccessful because of misunderstandings over meaning, as Gluch and Raisanen (2009) note,

"Communication is a dynamic and complex mediated discursive practice that both constructs and is constructed by human actors, using semiotic and technical tools...Communication needs to be viewed as social practice, involving the interaction of interlocutors, contexts, 
semiotic systems, artefacts and technologies. In this interaction there often exist inherent tensions between these elements in particular contexts of use.” (p. 165-166)

A semiotic perspective of briefing would focus upon the making of meaning, as Dainty et al. (2006) note,

"Whereas the process perspective sees communication as the transmission of messages through which one person seeks to influence another (and hence focuses on how transmitters and receivers encode and decode messages), the semiotic method sees communication as the development and exchange of meaning" (p.59)

This paper draws these strands of scholarship together, exploring the social nature of briefing and the criticality of shared meanings and understandings (Emmitt and Gorse, 2007) via requirement representation. The paper takes as its`starting point the "local rhetorical events" (Fleming, 1996) of design work practice, focusing upon client requirement representations. It contributes to recent work in the field (e.g. Aulich, 2013; Cheung et al., 2013; Jensen, 2011; Lee and Rojas, 2013) that continues to recognize the importance of communication and trust, but re-focuses attention upon the representation of requirements in the briefing and design process and how interpretations, meanings and understandings result from those representations.

\section{Social Semiotics}

Semiotics is the study of the functionality and use of signs in communicative interactions (Cobley, 2010). Danesi (2010) provides the following definition:

"The overarching aim of semiotics is to study the production and comprehension of signs as it manifests itself in human and non-human spheres." (p.135) 
Social semiotics is oriented towards understanding the role of signs in social situations, the implications of sign deployment and the motivational drivers underlying their formulation. As Kress (2010) states,

"Social semiotics believes signs are "motivated", not arbitrary relations of meaning and form: the motivated relation arises out of the interest of the makers of signs...A social semiotic approach asks whose interest and agency is at work in the making of meaning? What meanings are being made? How is meaning being made and with what resources?” (p.57)

Examination of briefing sign communications can therefore potentially expose the authorial intentions behind their use; semiotic resources being much more than simple conveyors of information and data. Kress (2010) gives a succinct description of how scholars may investigate author motivations through a focused analysis of their sign communications,

"The inner constitution of the sign reveals the interest of the maker of the sign...it opens the possibility of a path to understanding what in the phenomenon or object to be represented was treated as criteria by the maker of the sign at the moment of representation. This can lead to an understanding of the sign-maker`s position in their world at the moment of the making of a sign.” (p.65)

Semiotics recognises that signs provide different resources for making meaning known as modes (e.g. speech; writing; images) (Kress, 2010). In communication, different modes can be used singly or in combination to convey meanings concurrently, becoming multimodal ensembles of meaning. For example, the London Underground map combines text, colour and imagery.

Multimodality investigates the social semiotic role of multimodal constructs in different contexts (Kress, 2010), describing how modes are used in sign communications and attending to the intermodal relationships and "divisions of labour" between them. A multimodal 
analysis of a communicative sign would potentially reveal the "interest" of the author as being reflected through the aspects of the object represented and the combination of semiotic modes chosen.

Signs connect the social world of their use with the cognitive understandings of people who interact and relate to them, the principle being embodied in Eco`s Model Reader (1979), figure 1. The Model Reader indicates how effective communication is based upon shared interpretations and understandings between sign authors and readers: signs being mobilized in social settings (e.g. face-to-face meetings; web conferences), but connecting with the mental understanding of participants engaged.

[insert figure 1 here]

As a referential model of communication, the Model Reader highlights how shared interpretations and understandings are critical to effective communication: signs and semiotic resources being the vehicles and mechanisms of meaning.

Although semiotic analysis does use a certain terminology, it provides an effective suite of techniques, as Harrison (2003) notes,

"The method is quite complex and introduces a great deal of new terminology which can appear pedantic to the outsider and requires elaborate explanation every time the method is used...but the method is effective in bringing out hidden meanings." (p.154)

Such a view of semiotic work is also echoed by Penn (2000) who comments,

"Semiology provides the analyst with a conceptual toolkit for approaching sign systems systematically in order to discover how they produce meaning. Much of its precision derives from a series of theoretical distinctions, which are captured in its distinctive vocabulary." (p.227) 


\section{Analytic concepts}

Semiotics uses specific vocabularies to facilitate analytical work, such terms having been developed by scholars to examine sign use in different fields (Penn, 2000). Concepts of coded/non-coded; denotations/connotations and linguistic/iconic can be applied to textual, visual and multimodal signs to understand how they convey meanings.

Coded/non-coded: non-coded signs are simple to understand as compared to coded signs that require specialized knowledge. Non-coded signs are easily comprehensible and facilitate faster communication whilst coded signs are frequently used amongst professions or amongst closed groups. In a construction project context, schematic drawings will have coded signs which the client would not understand. Whether a sign is coded or non-coded depends upon the cognitive knowledge of individuals (i.e. their interpretive knowledge).

Denotations/connotations: denoted signs give direct meanings that do not depend upon cultural knowledge (Kress, 2010). They are direct, uncomplicated messages that are simply understood (e.g. the greeting "hello"; a knock on the door). Connoted meanings are secondary and often cultural. The words "Niagara Falls" denote a famous waterfall on the American/Canadian border, but may also have connotations for different people (i.e. "a honeymoon holiday"; "a dangerous boat trip"). Connoted meanings are always secondary to denoted meanings. The concepts of denotation/connotation can be applied to both coded/non-coded signs.

Linguistic/iconic: Barthes (1977) noted that linguistic signs often accompany iconic signs (e.g. diagrams), functioning as either anchorage or relay to images. As anchorage, words label that which is depicted, informing the viewer how to interpret it (e.g. a textual label under a photograph). As relay, text complements image by adding further meanings (e.g. text 
on cartoon strips). Iconic signs resemble their object in some way (e.g. photographs, maps, diagrams) and are used extensively in construction project briefing work.

Whilst images convey meanings concurrently, there is a necessary temporal sequencing when text is used to communicate (i.e. word following word); text being a more "laborious" medium than visual imagery. The compositional choices made by authors when combining different semiotic resources together are pertinent to social semiotic analysis that investigates author intention and narrative strategies in the employment of semiotic resources in communications.

\section{Visual social semiotics}

Whereas Barthes (1977) distillates how images convey multiple meanings, visual social semiotic analysis views the "grammar" of visual compositions (i.e. their size, colour, visual orientations) as also adding to their meaning:

"Meaning can also be derived from the grammatical make-up of images as well as the elements of the images... what is expressed in language through the choice of different word classes, may, in visual communication, be expressed through the different uses of colour or different compositional structures. And this will affect meaning. Expressing something verbally or visually makes a difference." (Kress and van Leeuwen, 2006, p. 1-2)

Representational, interactive and compositional analytical techniques expose how visual images can make relationships between viewers and authors of signs.

\section{Representational analysis}

Representational distinctions can be made between narrative and conceptual visualizations, narrative images "telling stories" about events by depicting people, environments or objects; conceptual images "defining" or "classifying" people, places or things in conceptual rather 
than "realistic" ways. Conceptual representations often use diagrams, charts, flow-models or graphs to visualize concepts, representing objects in terms of class, structure or meaning that do not involve action. Jewitt and Oyama (2001) summarise the orientation of a representational analysis of a visual image, and how it may inform understanding of the social event within which it is embedded:

"Narrative representations relate participants in terms of "doings" and "happenings" of actions, events or processes whilst conceptual patterns represent participants in terms of their more generalized, stable or timeless "essences". The decision to represent something in a narrative or conceptual way provides a key to understanding the discourses which mediate their representation.” (p.141)

Applying narrative and conceptual representational analysis enables the role of communicative modes subsumed within visual images to be exposed and discussed, with author intention, purpose and effect being potentially identified and highlighted.

\section{Interactive analysis}

Interactive analysis examines how images define relationships between authors and readers. For example, the particular perspective of an image establishes an interactive and interpersonal relation between image author and reader: a "bird`s eye" view of an object, "from above" puts the viewer into a position of power over the object whereas an "ant's eye" view gives the opposite effect, an image holding a position of power over a viewer. Such compositional choices define how a viewer relates to an image. "Point of view" analysis has been conducted in work by Harrison (2003), Kress and van Leeuwen (2006) and Jewitt and Oyama (2001).

\section{Compositional analysis}


Compositional analysis examines how representational and interactive effects cohere to deliver meaningful messages; an image lacking compositional coherence failing to work as a convincing communicative device. Compositional analysis draws together representational and interactive analysis with its`own methods to clarify the social semiotic functioning of elements within an image. Information value highlights how image elements are located in order to take on various information roles; salience explains how image elements obtain reader attention (e.g. through colour; placement; size) whilst modality queries the validity and reliability of an image as compared to reality (i.e. how "real" it is) (Harrison, 2003). Modal analysis of an image is potentially significant in a construction project briefing context where client and designers are using representations in order to imagine a future built structures.

\section{Design Objects}

Design objects (e.g. models; pens; post-it notes) feature prominently in briefing work. A distinction should be made between objects that assist in the design process through utilitarian qualities (e.g. pens, pencils, plasticine, post-it notes) and resources that are used for the communication of ideas between parties (e.g. schematic drawings, IT visualizations). Design work objects such as pens, paper and post-it notes are infused with meanings through their semantic essence, but these meanings may be built upon with further meanings, as Barthes (1967) explains,

"Once a sign is constituted, society can very well re-functionalize it...this refunctionalization needs, in order to exist, a second order language which is by no means the same as the first functionalization" (p.42)

Objects of design such as marker pens and post-it notes convey meanings through their inherent properties even if not being distinctly semiotic entities. However, semiotic meanings may be ascribed to them (e.g. a post-it note can have words and pictures drawn on 
it; a pen may be placed onto a schematic drawing to indicate flow of people). Objects can therefore attain semiotic meaning through design work practice.

\section{Research Method}

A 4-year study into the design and construction of NHS hospitals in the United Kingdom examined client requirement communication and representation among construction project participants. A series of 21 semi-structured interviews with NHS representatives and hospital AEC (Architecture, Engineering, Construction) professionals clarified building and design work interactions and the use of project requirements. Interviews were supplemented by the collection of project materials (e.g., briefing documents, visual images, room data sheets, drawings). The interviews with the 21 NHS representatives and AEC professionals were semi-structured in nature; this format facilitating interesting lines of enquiry to be pursued. Occasionally, interviewees would refer to a specific design resource in order to clarify and explain their insights. In the selection of materials for the study, the contention of Prior (1997) was followed, who states,

"Qualitative research can not only start with the investigation of things (rather than persons), but can also examine links and connections between objects that cannot speak, yet nevertheless bear messages." (p.77)

The relational link between the resources analysed for the study was client requirements; the focus of this paper being the hospital departmental configuration requirements (the work reported here forms part of a larger PhD study: Collinge, 2014). Resources relating to the hospital departmental configuration requirements are examined separately, but in sequence, as used on the hospital construction project. A social semiotic analysis of each separate resource is combined with interviewee insights regarding the briefing and design process. Additionally, from a methodological perspective, by combining analysis of project resources 
with semi-structured interviews, the qualitative approach is novel in that it moves away from an over-reliance on the interview; something noted as too commonplace in construction project management qualitative research (c.f. Dainty, 2008).

\section{Clinical Adjacency Matrix}

"The first conceptual thing of the design is the clinical adjacencies. The biggest driver is what goes next to what. Does Imaging go next to Outpatients? Certain departments need to be next to each other. So which departments and wards need to be next to each other?" (Hospital Director)

At project initiation, hospitals commonly provide designers with a clinical adjacency matrix, specifying the desired location of departments with each other. Figure 2 is a cropped version of a clinical adjacency matrix issued to design teams.

[insert figure 2 here]

The matrix is composed of textual and visual signs, making it a multimodal ensemble. A social semiotic analysis of the matrix clarifies its functionality, use and purpose in the briefing and design process.

\section{Analysis}

Non-coded signs predominate on the matrix: the departmental labels and text message being rendered in English, a mode of communication project actors would understand. The accompanying message also acts as relay (Barthes, 1977) supporting and adding additional information for the viewer. The colours are non-coded signs: the red, orange, green formulation referencing the relative cultural "importance" of this combination (i.e. traffic light signalling codes). This cultural meaning is connotative for the viewer. The matrix grid pattern itself is also a non-coded construct as no specialized knowledge is required to 
comprehend that it is being used to cross-reference concepts by combining colour with text. Such organizing grids will be familiar to project actors from their educational and professional lives. The text is denotative: departmental names are represented with text of equal style and sizing, delivering a meaning of departmental equivalence. The preponderance of non-coded signs on the matrix assists its" functionality as a "simple" mode of communication. Visual imagery analysis also clarifies the intention of the hospital as matrix author. Through a combination of colours and grid pattern, preferred departmental locations are made explicit, with colours attaining "meaning" through the linguistic textual key that serves as anchorage (Barthes, 1977). Thus the colours have both denotative and connotative meanings through textual labelling and cultural reference to the "traffic signal" combination.

The matrix is a "conceptual" representation rather than a "narrative" depiction. Departmental relations are represented as abstract, coloured boxes, of equal size and measure, with no one department being prioritized over another. Conceptually, analytical visual representations simplify through reductionist presentation; the low modality (i.e. realness) (Harrison, 2003) of the matrix assisting its`purpose as a communicative device. However, this representation immediately simplifies and objectifies the real-life hospital dynamics of action between departments. The equal distancing, sizing and orientations towards the horizontal and physical axes giving the departments a symmetrical and presentational equivalence. As a result, the internal functions, communications and linkages, both physical (e.g. cabling; pipes) and service (e.g. patient pathways of a hospital) are absent from the matrix. All of these compositional choices were made by the hospital organisation as matrix author.

The conceptual nature of the matrix does not detract from its`significance as an information resource for design teams. Indeed, it provides significant information for designers, even if the abstract format minimizes information about individual departmental activities. However, the matrix is a "closed" communicative resource: information is minimalized and 
the matrix does not invite speculation. Whilst certain hospital departments may have "reputations" or be acclaimed as centres of excellence, any such connotations of meaning are masked through the semiotic representational equivalence of the matrix: neither departments nor functionalities are privileged over another.

The matrix also contributes to the building of an initial relationship between client and designers pivoting around the adjacency requirement representation; the matrix has a collective authorship and does not inform designers about the personalities or culture of the hospital. To explore such issues, designers must use the opportunities provided by briefing and design meetings. Additionally, the coloured elements positively engage the viewer, giving a feeling of control over departmental relations, informing designers (and hospital staff) that departments may be arranged and managed: the task is not impossible or unachievable. This is important from a practical point of view as the matrix needs to be a useable resource in briefing work.

Whilst conveying meaning by combining semiotic modes (text; colour; matrix grid) together, the compositional choice of the hospital has resulted in a simplified, focused and equivocal representation of functional dependencies. The matrix simplifies and objectifies the real world, enabling client and designers to reference the initial preferences of the hospital quickly. Communicating these requirements with text would be possible, but also laborious and difficult to quickly reference. The use of certain semiotic signs leads to the contention that the matrix is both practical design tool and strategically formulated communicative resource, establishing a method through which hospital departments may be understood and communicated.

In summary, the matrix is an abstract, conceptual and reductionist representation that has low modality. It enables the hospital to represent departmental locations in an organisationally 
neutral way, masking functional and service complexities of an operational hospital. The matrix achieves such meanings whilst also being a visual resource that assists the client and designers in briefing work. Through the use of coloured abstract block shapes, new "associations" have also been generated; subsequent resources relating to department locations also display similar semiotic characteristics. We can see in the matrix the gestation of the semiotic characteristics that provide an anchorage for these requirements through the design discourse.

\section{Perspex blocks}

"So what we did then, we had blocks of Perspex that were coloured and we allowed the users to put the blocks together; if you want this department next to that department you start to see how your building will grow." (Design Director)

The use of Perspex blocks provides evidence of designers directly engaging the client with the clinical adjacency requirements. The Design Director elaborated further,

"Yes, it was about trying to engage them. If you get them around a table and you start getting them to hold stuff and move them around, they get more engaged and talk about it more. If they can feel that they can work with you and have some kind of rapport even better. And they will start to open up."

\section{Analysis}

The Perspex blocks may be considered objects of design; Barthes (1968) noted that objects can have semantic meaning through their physical characteristics, but still retain the potential to make further meaning as semiotic resources. So, whereas drawings and visualizations are specifically communicative resources (being composed of signs to be interpreted), design objects (e.g. marker pens; post-it notes) also convey meaning via their constitution and "essence". Further "meanings" were assigned to the blocks in the briefing room when 
designers inform attendees that the blocks were dimensional scale miniatures of specific hospital departments; the blocks thus becoming representations of various hospital departments. The assigning of names to the blocks gives them a direct meaning (adding to the proactive use of the visual colours and dimensional sizing), transforming the "meaningless" blocks into multimodal semiotic resources. In this respect, the clinical matrix (which would be referenced whilst people move the blocks around) gives the blocks a certain "legitimacy" through the "coloured block" formula of representing the departments. They also provide a tangible link with the matrix; an established semiotic association being conveyed forward to the face-to-face client/designer meeting.

\section{A Project Manager commented,}

"Building a relationship is a key one and diffusing the tension is important...because you need to defuse the tension if possible, trying to make it fun and interesting. You need to establish a good, free-flowing relationship with the client. Striking a balance is important and a level of professionalism."

The physical blocks directly engage the client; the tactile, tangible objects creating a "physical connection" with the project. They facilitate intra-client communication and communication with the design team, enabling all participants around the table to learn about hospital functional operations they may not be aware of. Additionally, the blocks are potentially "fun" to handle, taking participants "back to their childhood". The sensory and aesthetic aspects of using the blocks is important for those participating: to touch, to feel and move objects around a table with colleagues being distinctly different to engaging in "mental" design activities with concepts. Kress $(2010,77)$ elaborates upon this aspect of the physicality of objects when discussing chess pieces on a board and how that aspect of the game makes it different to "mental chess". This interactive aspect is significant in a briefing 
process that may be pressured and difficult for participants: the blocks defuse the tension and invite hospital staff to potentially relax. Indeed, it is the physical characteristics of the blocks that influence design team choice to use them with the client. The coloured blocks also "open up" the hospital departmental locations to experiment and design, whereas the matrix restricted this kind of open enquiry by representing departments as static, abstract blocks of colour.

The representation of clinical adjacency requirements has been shifted to a physical and material form; the blocks opening up the dialogue process with the client, facilitating discussion, reflection and imaginative ideas to flow. The physical aspect adds to their value (from a designer perspective), as the client can become mentally (and physically) engaged in the design process. As relationship building devices, the blocks are very useful, fusing together form and meaning in a practical and strategically important way for the design team in this phase of the building process. Moreover, the collective Perspex blocks activity creates a shared experience for participants, to be referred to and remembered in future design work activity.

\section{Theatres slide}

"After we started to put these blocks together, it started to look like this... and this was just the architect turning those into more formalized images... Once you hit upon an idea which seems to fulfil the constraints and adjacencies, you start going into more detailed levels of design and committing to more design work." (Project Director)

The Theatres slide (figure 3) gives a visual representation of 2 levels of the hospital. This image was presented to the client in a group presentation following the Perspex blocks activity and is a further representation of hospital department configurations. 
It is important to recognize the different contexts within which slides may be used: slides possibly being used in a "stand-alone" capacity, as single communicative devices, or being one in a series of slides used in sequence in presentations, potentially accompanied by verbal commentary from a presenter. These variable factors are significant to the overall working of the slide, but its`core functionality as a communicative resource resides with the signs depicted that communicate to a viewer. Extrapolating a precise context of use does not detract from the validity of conducting a focused analysis of a slide as semiotic composition that make it work as a communicative device.

[insert figure 3 here]

\section{Analysis}

The slide combines text with visual imagery, being a multimodal resource. It presents departmental zones and structural building elements (supporting columns and externally facing room blocks) with textual and visual signs; a building structure starting to emerge in visual form. The text is non-coded and denotative, performing a naming function and providing anchorage for the visuals elements. The visual signs are also non-coded; the coloured zonal blocks demarcating different hospital areas, with linguistic labels giving the areas "meaning". The coloured zonal areas are still conceptual signs, but further details of design have been added: the diagnostic interventional platform is divided into distinct "blocks" whilst "day care beds" are indicated with separate small blue indications. Red lines with "inpatient access" \& "outpatient access" indications introduce patient and staff flow requirements onto the slide (something repeated and magnified in subsequent project resources). Through these visual elements, multiple meanings have started to be generated, with different requirements starting to be merged through visual presentation. 
The Theatres slide has a technical resonance about it; technical images being used in briefing work as designs evolve and become more distinct (generated by software packages). However, it still lacks detailed technical design data, designers choosing to omit such information, making it a client focused resource. Resources deployed by designers (and the signs they display) are considered carefully prior to any meeting with the client, as an interviewee reflected,

"They are not very literate at looking at drawings or models because they are medical experts. They are not familiar with the language of architectural design. I think that is interesting because if those 3 meetings spilled over into a 4 or 5 meetings, then efficiency goes out of the process.” (Company Director)

Clearly, communicative resources can either assist (or hinder) the design process, effecting the number of meetings needing to be done and any consequent increases in cost and time. From such a perspective, the slide can impact the design process from both a social and project perspective; the temporally strained briefing process demanding that designers have positive interactions with the client when they meet. The balance of coded to non-coded and denotative to connotative signs on design resources contribute to effective communications with the client.

Interactively, the slide formulates a relationship between viewer and subject matter presented, a perspective shot angle from "above", giving viewers a feeling of "power" over the design (Kress and van Leeuwen, 2006). The social distance of the structure also adds to this perception; the colours and graphical layout engaging the viewer whilst the non-coded signs assist in the communication process with the client. Compositionally, the slide provides further information value for the client as departments have started to be oriented around an embryonic structure. Here, a building form begins to emerge, becoming more distinct with 
the supporting columns through visual signs. The appearance of functionality issues is a necessary representational shift evident on this and subsequent resources relating to clinical adjacency issues.

With the Theatres slide, designers are using signs to approach hospital functionality issues, although tentatively, as wholehearted commitment to a design formula at this stage may be counter-productive and possibly resisted by the client. In this respect it should be noted that the modality of the slide is low: real-life is not represented in any tangible way, although a portion of the hospital structure is slowly coming into focus.

The analysis indicates how the Theatres slide has brought forward the conceptual and abstract features of previous briefing work (e.g. the coloured block formula) into a more “construction" focused resource. Narrative elements are carefully balanced against the need to present the client with a simple visual representation; the slide engaging the viewer by combining textual and visual signs together into a multimodal ensemble that brings hospital department arrangements together around an embryonic physical representation. Moreover, the image has a definite "construction" aesthetic, indicating that design work is moving more towards formal construction work. In these ways, the slide has a social impact through its` semiotic properties.

\section{Vertical Flows schematic}

"With a hospital department, you 've got to put the risers and M\&E in otherwise you start to formalize the design in terms of adjacencies and that gets unravelled...so you have to do the 2 together. They need to understand enough to know that it has to be there..." (Design

\section{Director)}

The Vertical Flows schematic (figure 4) represents hospital departments on a planned grid on a landscaped background. More data has been added as compared to previous resources (i.e. 
space measurements; flows into/around structure; vertical transportation areas). A corresponding key gives further information for the viewer.

[insert figure 4 here]

\section{Analysis}

The schematic is a multimodal ensemble as it combines text and visual semiotic modes. There is a mixture of coded and non-coded signs: text labels and numeric measurements being non-coded signs that are readily understandable. The dotted, coloured flow lines are coded signs; their meaning is given via the denotative key (which also serves as linguistic anchorage). The flow line colours also relate to the hospital zonal areas (i.e. outpatient flows and areas both being yellow). The majority of signs are denotative (the external green landscape; the arrow-head flows), but some nuanced connotative meanings are also assigned to the flow lines: the "clean FM" flow is rendered in green; the "dirty FM" is assigned a solid red line to indicate its swift removal from the facility. The arrow flow lines are an evolutionary step forward from the red lines depicted on the Theatres slide, the schematic building upon the associative link made between "flows" and visual lines made previously. The multiple denoted signs (numeric; grid overlay; hatched areas) combine together to convey a "construction" connotation; the "credibility" of the schematic being delivered via the signs presented to the viewer. An interviewed Healthcare Sector Leader commented upon the importance of addressing flow issues during briefing work,

"And now it is all about flow...flow of people (the patient pathways, visitors) and goods and services, bits of things which are not people. How do we get these things in and out without getting in the way of other things. And it is about knitting all those things together."

The schematic retains the coloured block formula for departments, providing semiotic anchorage to earlier work activities, but now an overlaying grid pattern has been added. The 
combination of grid pattern and numeric measurements indicate how the design is becoming more tangible. The schematic has a "technical" aesthetic, being generated from a computer software package. The technical connotation can be significant, potentially influencing client perspectives of design, as an interviewee noted,

"If you give them CADDED drawings, they look too formalized, look finished. And they feel as if they are being pressurized into accepting something. So it is important sometimes to sit down with a piece of paper and sketch, and use overlay tracing paper... as soon as your start to CAD things up, it tends to make it look too rigid in terms of a process." (Project Director)

The schematic is a "closed" design resource in that it is formalizing the design in definitive ways. Indeed, the effect of signs to "open" or "close" the design process was noted by an interviewed BIM Company Director,

"You are trying to reach a quick decision aren`t you so you don`t want it to be too open ended to a point where they might say "can we just turn that around". Don 't make it too easy for them..."

Client-facing design teams will have strategic intentions and motivations, reflected through signs employed to convey meanings to a viewer.

The white hatched area and the "plant" area are likely to be M\&E (mechanical \& engineering) areas. These are "coded" signs because the client may not possess the requisite knowledge to understand their meaning (and the functionality issues behind them). The design team may need to educate the client about these issues. Therefore, certain semiotic constructs on the slide can become triggers for client-facing educational work. As indicated, education and learning can potentially be a two-way process in briefing work and semiotic signs mobilized can be the conduits for such activity. Such instances may become 
increasingly possible as requirements cohere and combine together as designs mature. Therefore, signs can be triggers of learning (and more briefing work), making their inclusion (or not) important in the context of a time-constrained briefing process.

Compositionally, the slide brings together sign combinations relating to different project requirements onto one schematic. Slide salience (visual effectiveness) is achieved by designers through judicious use of colours and a compositional layout that engages viewer attention. The modality of the slide remains low (the representation still lacks "realness") although the inclusion of flow lines and M\&E details does begin to add functionality and authenticity to the design.

Overall, the schematic is a multimodal ensemble that presents a further conceptual view of departmental requirements but pushes the design forward through the inclusion of more sign constructs. As noted, these signs can trigger necessary educational initiatives from both the client and designer side, also creating meaning across several project stakeholder groupings concurrently (e.g. facilities managers; nurses, etc.). The need to inform the client of design progress is assisted by the Vertical Flows schematic: the visual representation bringing forward adjacency requirements onto a more construction focused design resource.

Hospital departments continue to appear in subsequent design resources generated by designers but are no longer an explicit focus of attention. Having obtained client approval of departmental configurations, design work effectively proceeds to other issues.

\section{Discussion}

The paper has detailed how clinical adjacency requirements are represented and transformed using a variety of semiotic resources in briefing work. By taking forward the assertion of Fleming (1996) that briefing may be clarified through a close examination of "local rhetorical 
events" (p. 140-142), the semiotic analysis of specific resources highlighted the significance of different communicative resources for client requirement representation.

Three broad contentions can be made from the analysis: meanings are delivered through representations; new meanings can be made through representations; project relationships are affected through such representations.

\section{Delivering specific meanings}

Signs are used to deliver specific meanings in briefing work. Direct denotative signs convey factual data through numbers (e.g. room size dimensions) and words (e.g. as labels on drawings). Factual data is necessary for construction project collaborative design work (Blyth and Worthington, 2001; Kamara et al., 2002) and non-coded denotative signs facilitates quick comprehension and speedy communication. It is conceivable that such data may be "captured" and used in IT software packages (Kamara et al, 2002). However, as the paper argued, signs are not just simple conveyors of data, but are also socially significant meaning making resources.

Sign combinations are also used to deliver specific denotative and connotative meanings concurrently. For example, the colours, grid pattern and text on the clinical adjacency matrix deliver departmental preferences denotatively and connotatively concurrently. The use of representational, interactive and compositional effects enables sign authors to deliver specific meanings to receiving parties in distinct ways, so that semiotic resource use is intrinsic to how requirements are represented and how meanings are delivered in briefing and design work.

\section{Formulating new meanings}


Signs are used to formulate new meanings in design work. In this respect, imagery is a potent resource, especially as a particular representation of a requirement in a new visual way may not be closely scrutinized by a viewer and may escape examination.

New meanings may enter the briefing process when objects are used to facilitate interactive design work: the Perspex blocks activity pivoting on the formulation of new meanings between participants through object use. In the resulting interaction, semiotic resources are used to make further meanings in a co-operative and social briefing process: the formulation of new meanings between parties creating cohesion and unity across the briefing table.

However, in a temporally constrained briefing process, new meanings may require education and learning (and time). For example, the use of coloured flow lines and the M\&E riser graphic on the Vertical Flows schematic potentially requires explanation. The initiation of new learning may be considered by designers prior to the presentation of a design to the client or may result from a need to share knowledge. Because hospital construction projects bring together health and medical experts with AEC (Architecture, Engineering, Construction) professionals, the possibility of new learning may be high.

\section{Relationship building devices}

Signs have implications for the relationship between client and design teams and influence how the client relates to their own requirements. Designers use semiotic resources to build a relationship with the client: the proactive use of Perspex blocks in open, interactive activities, enables designers to form a relationship with the client. Similarly, the use of signs with a distinct "construction connotation" nudge the client towards construction focused work and away from an open discussion of issues, closing down some requirements and opening up others for scrutiny. Additionally, signs can also indicate and assert the construction credentials of a design team to the Trust client, which is important in a competitive bidding 
context. A dual aim of engaging the hospital client and controlling the design evolution process can be discerned and effected through semiotic resource use.

Signs also establish relationships between the client and their own requirements, designers using semiotics to influence how the client perceives and understands their own requirements. The clinical adjacency matrix represents requirements in an anonymous and organisationally neutral way. Client representatives start to question, query and explain their own requirement needs once direct briefing work begins with designers, providing they have an opportunity to do so (e.g. through interactive design workshops). Signs can perform several functions concurrently when subsumed within one single design: adjacency matrix and coloured Perspex blocks being resources that deliver meanings, formulate new meanings and build relationships between parties concurrently through their semiotic meaning making properties.

\section{Briefing as social semiotic practice}

Although requirements are a primary driver in design work, being a tangible link to the client throughout the construction project process (Barrett and Stanley, 1999), the representational shifts they undergo often escape notice. However, the representation of requirements and their subsequent interpretation provides a vital link between project stakeholder interest and the potential realisations of design as formulated by architects, engineers and designers. As illustrated in Figure 1, signs connect the social world of their use with the cognitive understandings of people who interact and relate to them. The paper has articulated how the representation of requirements can have social implications that are as significant as the factual data they convey; client requirement representation being central to the meaning making process that characterizes briefing and design work. 
The findings support the view that briefing is more than an exchange and processing of information, but is a social process where relationships are socially formed and meanings socially shared (Emmitt and Gorse, 2007). Whilst information exchanges have been identified as central to the design process (Baldwin et al., 1999), the paper has explored how understandings and meanings are shared through resource use, with construction project meaning making being a semiotic process (Dainty et al., 2006; Gluch and Raisanen, 2009). As a result, the paper has provided a semiotic view of communication rather than a processual one.

As noted, sign formulations are critical for the formation of meanings, but meanings can also be made by other project phenomenon: behaviours in a Board room; spoken dialogue; hand gestures or the personalities of individuals all conceivably contributing to the meaning making process. Eco (1979) describes the process of interpretation as being a continuous, complex, interconnected cognitive "coming and going" by the reader (p.36). In briefing work, layers of meaning are generated that have a cumulative effect. For example, when a design drawing is examined by a project team, spoken language will sit on top of the drawing to add further meaning to it. Personalities and actions of individuals around the table will also potentially add further meanings. In this way, layer upon layer of meaning is made as new signs are layered upon existing signs. It should be remembered that in project contexts, design resources do not function in isolation, but are part of complex collaborative environments that involve multiple and shifting stakeholders. The processes of making meaning are inherently complex, with the semiotic representation of requirements being a necessary aspect of briefing and design work. The process of making meaning begins with the initial briefing documentation and proceeds with the production and use of various design resources (e.g. schematics; images; interactive objects). From such a perspective, briefing and design may be understood as social semiotic practice. 
The issues discussed also re-focus attention on the important question of representation. In an industry increasingly dominated by IT applications such as BIM (Eastman et al., 2008; Scheer, 2015), how and with what resources client requirements can be represented continues to be a potentially relevant area of innovation and experimentation. That some requirements are intangible and resist representation (even with advanced visual technologies) has been noted (e.g. infection control - Collinge, 2015); as has the increasing use of immersive digital technologies in design practice (Maftei and Harty, 2015).

\section{Conclusion}

The paper explored the use of semiotic resources for the representation of construction project requirements through the briefing and design process. Through a social semiotic study, the functionality and purpose of sign communications employed by the client and designers has been exposed to scrutiny: the steady semiotic transformation of requirements being intrinsic to the making of meanings in briefing and design work. It has also been argued that appreciation of the social aspect of meaning formulation is important in a design process that can be competitive, temporally constrained and stressful for participants. By theoretically and analytically exploring how requirements are successively represented in design work, the paper builds upon the work of scholars who have identified semiotic processes as being intrinsic to construction project design communications.

In the journey from initial brief to a set of agreed design specifications, semiotic resource use enables designers to engage the client in co-operative, interactive processes of learning that can be controlled through the proactive use of text, visual imagery and objects. In the meaning making process, sign communications contribute both procedurally (via delivery of data) and socially (as relationship building resources), either opening up or closing down the design process for both client and designers in strategic and political ways. It is a contention 
of the paper that the representation of requirements through semiotic resource use is intrinsic to design work practice, the consequences of which should be considered carefully by professionals and practitioners.

\section{References}

Aulich, T. (2013), "The role of effective communication in the construction industry: a guide for education and health clients", Australian Journal of Construction Economics and Building, Vol. 13 No.4, pp.92-101.

Baldwin, A. N., Austin, S.A., Hassan, T.M. and Thorpe A. (1999), "Modelling information flow during the conceptual and schematic stages of building design”, Construction Management and Economics, Vol.17 No.2, pp.155-167.

Barrett, P. and Stanley, C. (1999), Better Construction Briefing, Blackwell Science, Oxford.

Barthes, R. (1967), Elements of Semiology. Cape, London.

Barthes, R. (1977), The Rhetoric of the Image, In Image, Music, Text. Fontana, London.

Blyth, A. and Worthington, J. (2001), Managing the brieffor better design, Spon, London.

Bogers, T., van Meel, J.J. and van der Voordt, T.J.M. (2008), “Architects about briefing”, Facilities, Vol.26 No.3/4, pp.109-116.

Cheung, S.O., Yiu, T.W. and Lam, M.C. (2013), "Interweaving trust and communication with project performance", Journal of Construction Engineering and Management, Vol.139 No.8, pp.941-950.

CIB (Chartered Institute of Building) (2010), Code of practice for project management for construction and development, Wiley-Blackwell, Oxford.

Cobley, P. (2010), The Routledge Companion to Semiotics, Routledge, London. 
Collinge, W.H. (2014), "Briefing as meaning making practice through signs: Client requirement representations and transformations in construction project design", $\mathrm{PhD}$ thesis, Department of Construction Management \& Engineering, University of Reading, United Kingdom.

Collinge, W.H. (2015), "Infection control in design and construction work", Health Environments Research and Design Journal, Vol.8 No.3, pp.68-79.

Dainty, A. (2008). "Methodological pluralism in construction management research”, In: Advanced Research Methods in the Built Environment (Eds: Andrew Knight and Les Ruddock). Chichester, Wiley Blackwell.

Dainty, A., Moore, D. and Murray, M. (2006), Communication in construction: Theory and Practice, Taylor and Francis, Oxon.

Danesi, M. (2010), "Semiotics of media and culture”, In: Cobley, P. (Ed.) The Routledge Companion to Semiotics, Routledge, London, (pp. 135-149).

Eastman, C.M., Teicholz, P., Sacks, R. and Liston, K. (2008), BIM Handbook: a guide to building information modelling for owners, managers, designers, engineers and contractors, Wiley, Hoboken, NJ.

Eco, U. (1979), The role of the reader, Indiana University Press, Bloomington.

Egan, J. (1998), Re-thinking construction: report of the construction task force, HMSO: London.

Emmitt, S. and Gorse, C. (2007), Communication in construction teams, Taylor and Francis, Oxon. 
Fernie, S., Green, S.D. and Weller, S.J. (2003), "Dilettantes, discipline and discourse: requirements management for construction", Engineering, Construction \& Architectural Management, Vol.10 No.5, pp.354-367.

Fleming, D. (1996), "Professional-client discourse in design: variation in accounts of social roles and material artifacts by designers and their clients", Text, Vol.16 No.2, pp.133-160.

Gluch, P. and Raisanen, C. (2009), "Interactional perspective on environmental communication in construction projects", Building Research \& Information, Vol.37 No.2, pp.164-175.

Goodacre, P., Pain, J., Murray, J. and Noble, M. (1982), Research in Building Design, Occasional Paper No.7., Department of Construction Management, University of Reading.

Green, S. D. (1996), “A metaphorical analysis of client organizations and the briefing process", Construction Management and Economics, Vol.14 No.2, pp.155-164.

Harrison, C. (2003), “Understanding how still images make meaning”, Technical Communication, Vol.50 No.1, pp.46-60.

Jensen, P.A. (2011), "Inclusive briefing and user involvement: case study of a media centre in Denmark", Architectural Engineering and Design Management, No.7, 38-49.

Jensen, P.A. and Pedersen, E.F. (2009), "User involvement and the role of briefing", In: S. Emmitt, M. Prins and A. den Otter (Eds.) Architectural Management - International Research and Practice, Chichester, Wiley-Blackwell.

Jewitt, C. and Oyama, R. (2001), "Visual Meaning: a social semiotic approach”, In van Leeuwen, T. and Jewitt, C. (eds) Handbook of Visual Analysis, Sage, London. 
Kamara, J. M., Anumba, C.J. and Evbuomwan, N.F.O. (2000), "Establishing and processing client requirements - a key aspect of concurrent engineering in construction”, Engineering, Construction \& Architectural Management, Vol.7 No.1, pp.15-28.

Kao, C. and Green, S.D. (2002), “The briefing process: a knowledge management perspective", Paper presented at the CIB Value Through Design Conference Rotterdam (eds: Gray, C. and Prins, M.), pp.81-92.

Kress, G.R. (2010), Multimodality : a social semiotic approach to contemporary communication. Routledge, New York.

Kress, G.R. and van Leeuwen, T. (2006), Reading images: the grammar of visual design. Routledge, London.

Latham, Sir Michael (1994), Constructing the Team. HMSO, London.

Lee, N. and Rojas, E.M. (2013), "Visual representations for monitoring project performance: developing novel prototypes for improved communication”, Journal of Construction Engineering and Management, Vol.139 No.8, pp.994-1005.

Lloyd, P. and Busby, J. (2001), "Softening up the facts: engineers in design meetings", Design Issues, Vol.17 no.3, pp.67-82.

Maftei, L. and Harty, C. (2015), "Designing in caves: using immersive visualizations in design practice", International Journal of Architectural Research, Vol.9 No.3, pp.53-75.

Markus, T.A. and Cameron, D. (2002), The words between the spaces: buildings and language. Routledge, London.

Penn, G. (2000), “Semiotic analysis of still images”, In: Bauer, M.W. and Gaskell, G. (Eds.) Qualitative researching with text, image and sound. A practical handbook, Sage, London, pp. $227-245$. 
Prior, L. (1997), "Following in Foucault`s footsteps: text and context in qualitative research", In: Silverman, D. (Ed) Qualitative research: theory, method and practice, Sage, London, pp. 63-79.

Ryd, N. (2004), "The design brief as carrier of client information during the construction process", Design Studies, Vol.25 No.3, 231-249.

Scheer, D. R. (2015), The death of drawing: architecture in the age of simulation. Routledge, New York. 


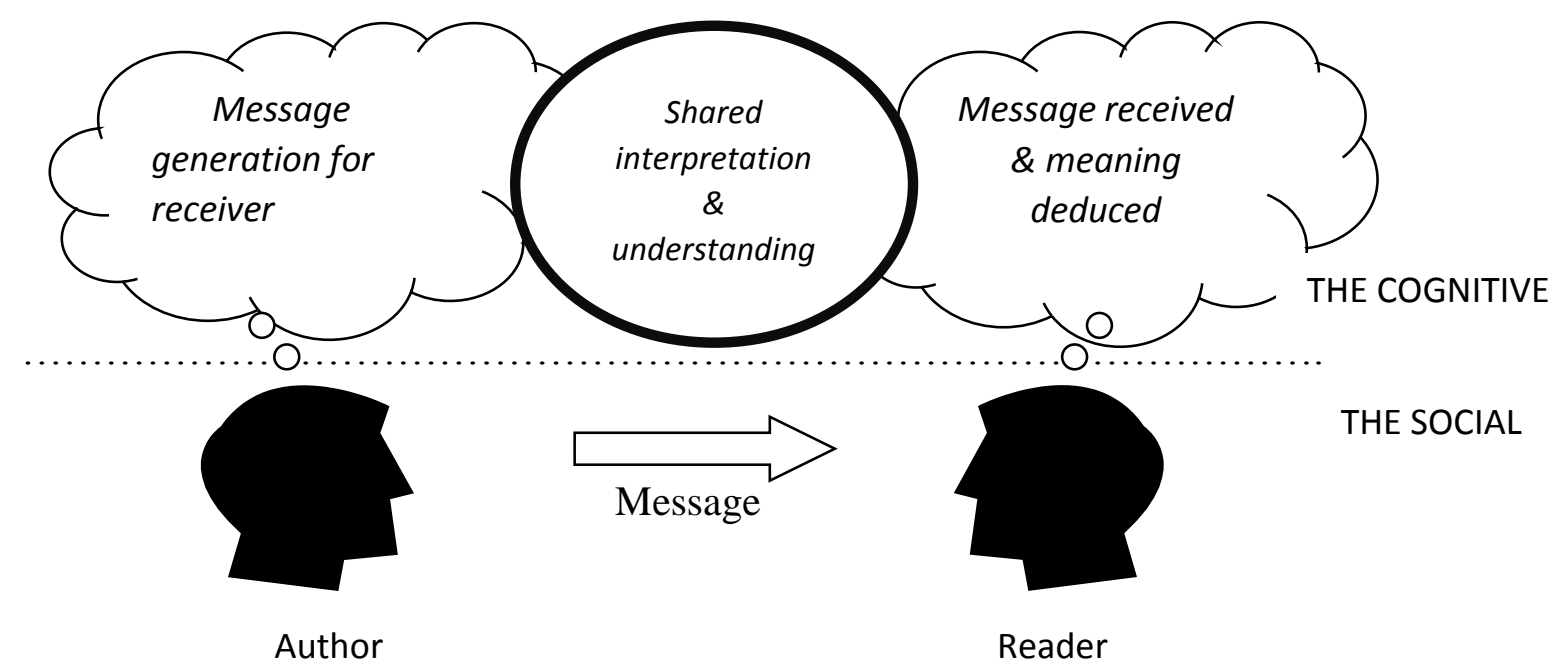

Figure 1: Model Reader visualization (based on Eco, 1979) 


\begin{tabular}{|l|l|l|l|l|l|l|l|}
\hline Department & $\begin{array}{l}\text { Main } \\
\text { entrance }\end{array}$ & $\begin{array}{l}\text { Emergency } \\
\text { Entrance }\end{array}$ & Outpatients & $\begin{array}{l}\text { Ambulatory } \\
\text { testing }\end{array}$ & $\begin{array}{l}\text { Radiology \&uc.Med } \\
\text { Nuth }\end{array}$ & $\begin{array}{l}\text { Cay case } \\
\text { Ward }\end{array}$ \\
\hline $\begin{array}{l}\text { Main } \\
\text { entrance }\end{array}$ & & & & & & & \\
\hline \\
\hline $\begin{array}{l}\text { Emergency } \\
\text { Entrance }\end{array}$
\end{tabular}

\begin{tabular}{|l|}
\hline Key \\
\hline Essential \\
\hline Important \\
\hline Desirable \\
\hline
\end{tabular}

This adjacency matrix should be read in conjunction with the relevant clinical output specifications

Figure 2: clinical adjacency matrix

(image courtesy of HOK Architects) 


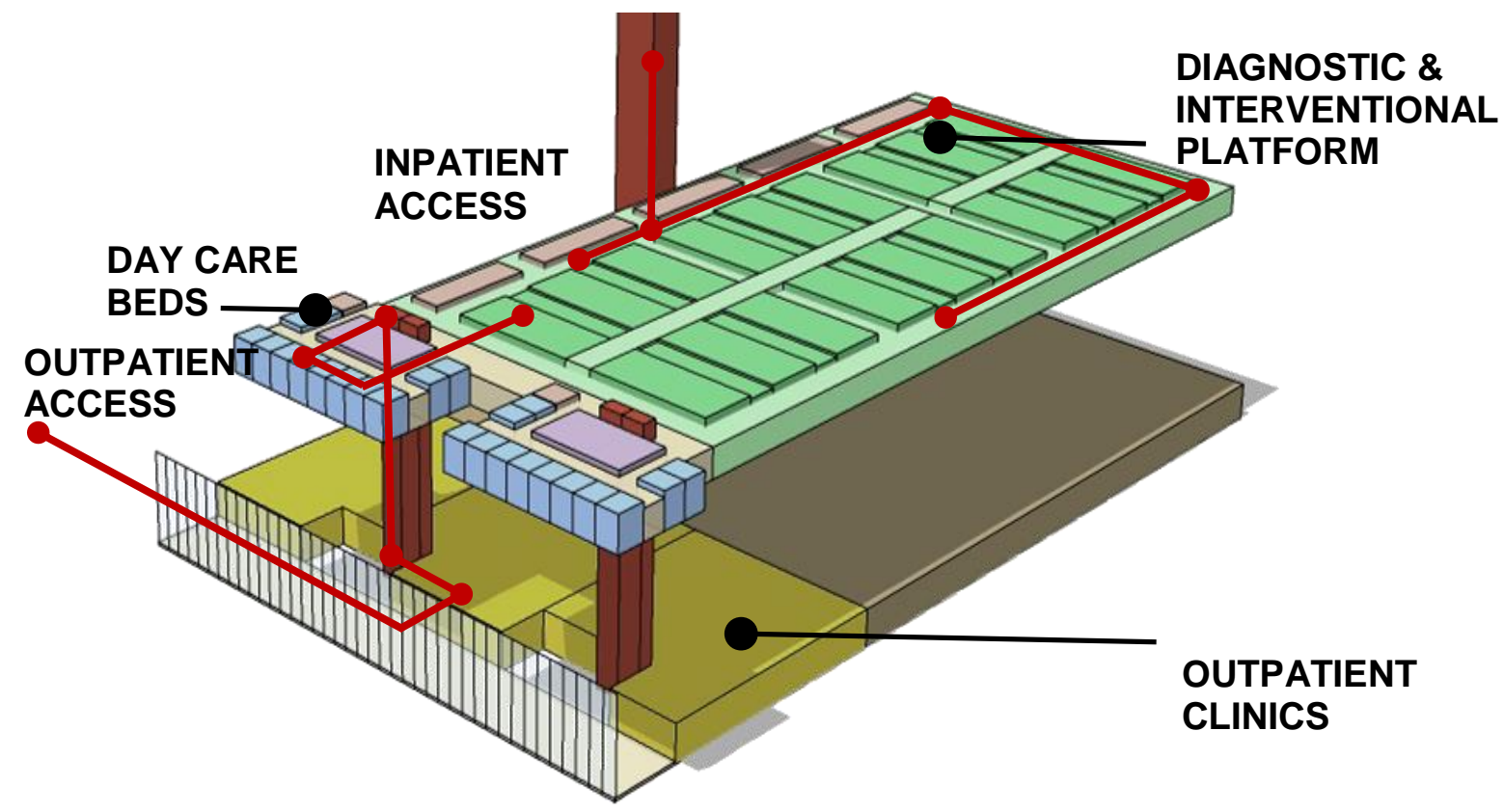

Figure 3: Theatres Images and Flows slide

(image courtesy of HOK Architects) 


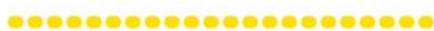

$\bullet \bullet \bullet \bullet \bullet \bullet \bullet \bullet \bullet \bullet \bullet \bullet \bullet \bullet \bullet \bullet \bullet \bullet \bullet \bullet \bullet \bullet \bullet$

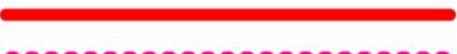

INPATIENTS

$\bullet \bullet \bullet \bullet \bullet \bullet \bullet \bullet \bullet \bullet \bullet \bullet \bullet \bullet \bullet \bullet \bullet \bullet \bullet \bullet$ STAFF

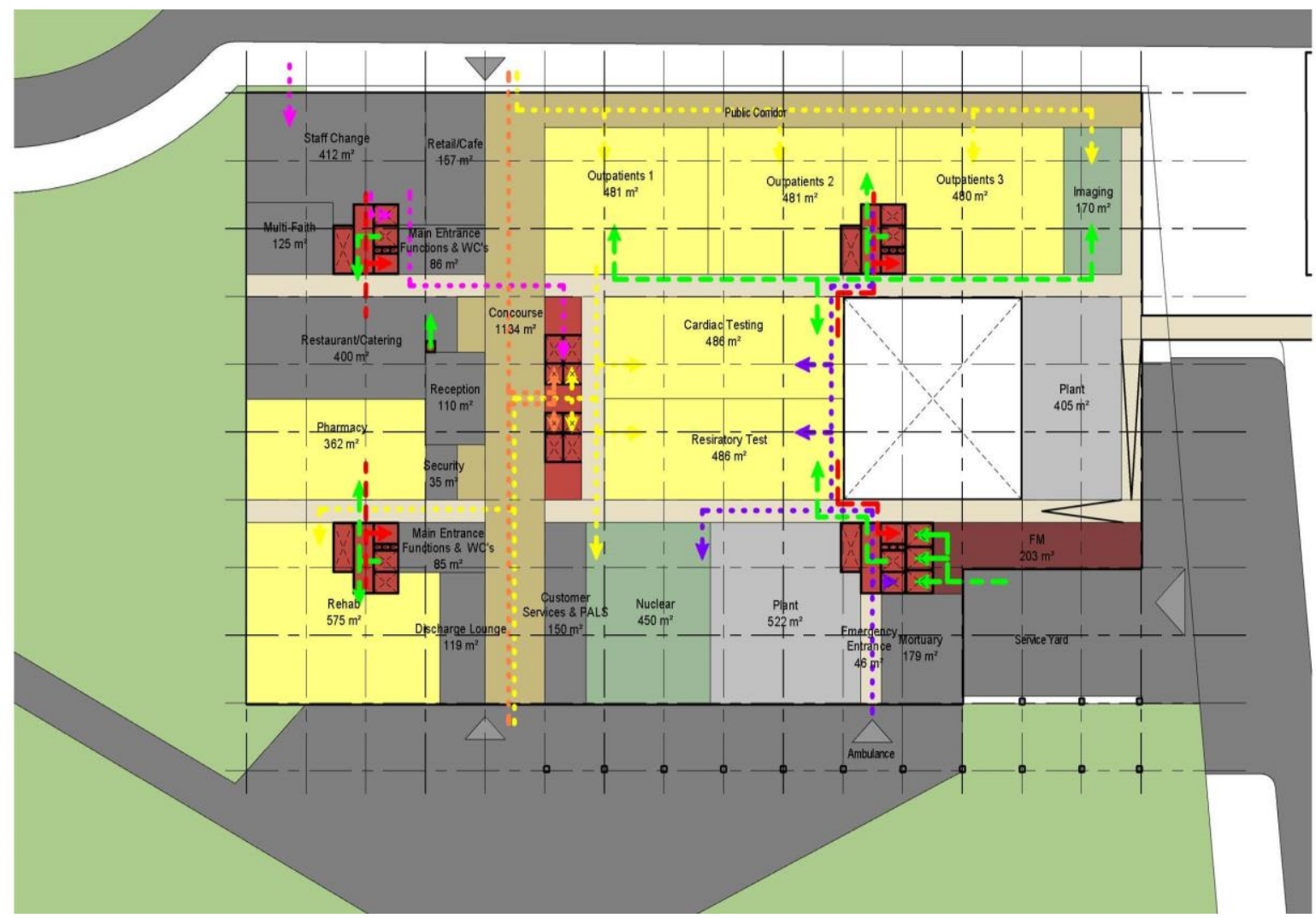

Figure 4: Vertical Flows schematic

(image courtesy of HOK Architects) 